\title{
Pedicellar structures in Reduviidae (Heteroptera) - comments on cave organ and trichobothria
}

\author{
Christiane WEIRAUCH \\ Freie Universität Berlin, Institut für Biologie/Zoologie, AG Evolutionsbiologie, Königin-Luise-Strasse 1-3, 14195 Berlin, Germany; \\ e-mail: cweir@zedat.fu-berlin.de
}

Key words. Antenna, trichobothrium, cave organ, morphology, phylogenetic systematics, Heteroptera, Reduviidae

\begin{abstract}
Sensillar structures of the antennal pedicel are investigated in Reduviidae and Pachynomidae. The cave organ, a presumably chemoreceptive structure, previously reported only for haematophagous Triatominae, is described here also for representatives of Peiratinae, Reduviinae and Stenopodainae. The systematic implication of the occurrence of this sensillar structure is discussed. Further, four sclerites located in the membrane between pedicel and preflagelloid are described and used as landmarks for the recognition of individual trichobothria in Reduviidae and Pachynomidae. Characters of the trichobothrial socket are studied and discussed systematically. Homology of the distalmost trichobothrium of Reduviidae with the single trichobothrium in Pachynomidae is proposed. This hypothesis is based on the structure of the cuticle surrounding the trichobothria and on the trichobothrial position relative to the four sclerites of the pedicello-flagellar articulation. The single trichobothrium present in most nymphs corresponds to the distalmost trichobothrium in adult Reduviidae in position and structural detail. A reasonable hypotheses on the homology of individual trichobothria of the proximal row or field seen in most Reduviidae can so far only be formulated for Peiratinae.
\end{abstract}

\section{INTRODUCTION}

Several features of the antennae of Heteroptera have been the subject of systematic observation and interpretation in recent years. Apart from an examination of antennal sclerites (Zrzavý, 1990a), the presence and distribution of sensory structures have especially attracted interest (McIver \& Siemicki, 1984; Wygodzinsky \& Lodhi, 1989; Zrzavý, 1990b; Catalá, 1997; Gracco \& Catalá, 2000). Barth (1952) noted a presumably sensory structure within the distal portion of the pedicel in haematophagous Triatominae. This structure was recently described in detail in representatives of Rhodnius, Triatoma and Panstrongylus (Triatominae) and referred to as "cave organ" (Catalá \& Schodfield, 1994; Catalá et al. 1998). In these taxa, the cavity is 40 to $150 \mu \mathrm{m}$ long and its epithelium contains bipolar neurons with sensillar projections (Catalá et al. 1998). Suggested functions of this structure in haematophagous Triatominae include response to heat stimuli (Barth, 1952; Lazzari \& Wiklein, 1994) or chemical cues (Catalá et al., 1998). There is one ambiguous indication of this structure in non-haematophagous Reduviidae. Dougherty (1985) described an opaque oval structure around the distalmost pedicellar trichobothrium in Ectrichodiinae which she referred to as part of "Barth's organ", considering it the structure described by Barth (1952). In the present study, the pedicels of representatives of 18 higher rank taxa of Reduviidae and of representatives of its sistergroup Pachynomidae are examined for the cave organ.

Other sensory structures reinvestigated in this study are trichobothria present on the antennal pedicel in Reduviidae and Pachynomidae (Wygodzinsky \& Lodhi, 1989; Zrzavý, 1990b). Trichobothria are long, slender and erect mechanoreceptive setae which often posses a prominent socket and may respond to air movements (Schuh, 1975). Within Heteroptera, trichobothria may occur on various parts of the body and appear to be of systematic value in several groups (Schaefer, 1975; Schuh, 1975). Reduviidae and their sistergroup Pachynomidae (Carayon \& Villiers, 1968) possess different numbers and arrangements of trichobothria on the pedicel (Wygodzinsky \& Lodhi, 1989). Their pattern was interpreted in a phylogenetic scheme by Zrzavý (1990b). He divided the pedicel into proximal and distal parts and defined six types of trichobothrial patterns according to number of trichobothria present in the respective compartment. These types of trichobothrial patterns were then assigned to reduviid subfamilies arranged according to the phylogenetic scheme by Puchkov (1987). This study aims to provide further structural and positional information on the antennal trichobothria in Reduviidae and Pachynomidae which might lead to the proposition of homology of individual trichobothria among taxa.

\section{MATERIAL AND METHODS}

To study the cave organ and the pedicellar trichobothria, entire antennae were cleared in $\mathrm{KOH}(10 \%)$ for 12 to 24 hours at room temperature. In so treated antennae only sclerotised structures are retained. Structures of the cave organ visible after this treatment are the cuticular invagination, including the cuticle-lined sensory projections. Depending on colour and degree of sclerotization, pedicels with only faint contrast were stained with Chlorazol Black E after clearing. Antennae were mounted in glycerol on slides and observed on a Leitz Diaplan and a Leitz Axioplan. Drawings were made using a camera lucida on the Leitz Diaplan. Photographs were taken with a Fujifilm FinePix S1 Pro digital camera. To check for individual variation, usually pedicels of both antennae of each specimen were used as well as antennae of several specimens when possible. 
For scanning electron microscopy, antennae were removed from the head, cleaned in warm water with detergent, dehydrated, critical point dried in a BAL-TEC CPD 030, coated with gold in a BALZERS UNION SCD 014 and observed in a PHILIPS SEM 515 or a LEO 430

For histological study of the trichobothrial socket and the pedicello-flagellar articulation, a $5^{\text {th }}$ instar nymph of Triatoma dimidiata (Latreille) and a $5^{\text {th }}$ instar nymph of Peirates sp. were fixed in an alcoholic-acetic acid-formalin (8:1:1) - fixative or $70 \%$ alcohol respectively. Entire heads were removed, dehydrated and embedded in Kulzer's Technovit 7100. $2 \mu \mathrm{m}$ sections were obtained on a R. Jung microtome, transferred to slides, stained with eosine and toluidine blue, and covered using Eukitt and cover slips dipped in Rotihistol.

Supplementary investigation of trichobothrial arrangements of taxa not examined by Wygodzinsky \& Lodhi (1989), the Ectinoderinae and Diaspidinae, were carried out on a dissection microscope

Representatives of the following taxa were observed with the light microscope. Species examined additionally in the SEM are marked with a $(\mathrm{S})$. $(\mathrm{N})$ indicates that nymphs were observed, (M) stands for male and (F) for female. (DM) refers to observation with the dissection microscope only, which allows statements on number and arrangement of trichobothria as well as presence or absence of an oval membrane surrounding trichobothria. It does not allow the observation of the presence or absence of the cave organ and structural detail of the trichobothrial socket.

The extent and arrangement of subfamilies follows Maldonado Capriles (1990) and Putchkov \& Putchkov (1985-1989). The term "harpactoroid groups" is employed sensu Davis (1969).

Apiomerinae: Apiomerus barbiellini Costa Lima, Campos Seabra \& Hathaway (M, S), Apiomerus erythromelas Blanchard (M), Heniartes flavicans (F.) (M, S); Centrocneminae: Neocentrocnemis sp. (DM); Cetherinae: Cethera musiva (Germar) (M), Eupheno pallens (Laporte) (M, F); Diaspidinae: Diaspidius sp. (N, DM); Ectinoderinae: Ectinoderus nitidus Stål $(\mathrm{N}$, DM); Ectrichodinae: Brontostoma colossus (Distant) (M), Brontostoma sp. (F), Ectrichodia crux (Thunberg) (M, F), Nularda nobilitata Stål (M); Emesinae: Metapterini: Ghilianella filventris Spinola (M); Ploiariolini: Empicoris xambeui (Montandon) (M); Hammacerinae: Homalocoris varius (Perty) (M), Microtomus sp. (M, N); Harpactorinae: Cosmoclopius intermedius Berg (M, F, S, N: LM, S), Havinthus rufovarius Bergroth (M), Helonotus sextuberculatus Malipatil (M), Isocondylus elongatus (Lepeletier \& Serville) (F), Phonoctonus lutescens (Guérin \& Percheron) (M, F, S, N: LM, S), Pristhesancus plagipennis Walker (F), Rhynocoris erythropus (L.) (M, F, N: LM, S), Ricolla quadrispinosa (L.) (M), Rocconota sp. (N: LM), Zelus sp. (N: LM); Holoptilinae: Ptilocnemus sp. (M); Peiratinae: Ectomocoris sp. (M), Melanolestes morio (Erichson) (M), Peirates stridulus (F.) (F, M), Peirates sp. (N, histological observation), Rasahus amapaensis (Coscarón) (M), Sirthenea stria (F.) (F, M) (Fig. 4g), Tydides rufus (Serville) (M); Phymatinae: Phymata monstrosa (F.) (M, F, N), Phymata praestans Handlirsch (M); Physoderinae: Physoderes sp. (M); Reduviinae: Acanthaspis sp. (M), Alloeocranum maculosum Distant (M), Centrogonus signatipennis (Reuter) (M), Leogorrus liturata $(\mathrm{F}).(\mathrm{M})$; Opisthacidius chinai Lent \& Wygodzinsky (M), Paredocla planquettei Villiers (M, F), Platymeris biguttata (L.) (F, M, S), Reduvius personatus (L.) (M, F), Reduvius tenuicornis (Jakovlev) (M, F), Velitra sp.1 and $2(\mathrm{M})$, Zelurus spinidorsis (Gray) (M); Saicinae: Oncerotrachelus sp (M), Polytoxus sp. (M, F); Salyavatinae: Lisarda sp. (F); Ste- nopodainae: Apronius octonotatus Champion (M), Diaditus sp. (M), Kodormus bruneosus Barber (M), Oncocephalus sp. (M, F), Pnirontis sp. (M), Pygolampis bidentata Germar (M), Pygolampis spurca Stål (M), Staccia diluta (Stål) (M), Stenopoda subinermis Stål $(\mathrm{M})$, Thodelmus impicticornis Stål $(\mathrm{M})$; Tegeinae: Tegea atropicta Stål (M, F, S); Triatominae: Rhodniini: Rhodnius prolixus Stål (M, F); Triatomini: Dipetalogaster maximus (Uhler) (M, F, N), Eratyrus mucronatus Stål (M), Panstrongylus geniculatus (Latreille) (M), Triatoma dimidiata (Latreille) (M, F, N: histological observation); Tribelocephalinae: Opistoplatys sp. (M), Tribelocephala sp. (M), Vesciinae: Chopardita mira Villiers (M, DM), Pessoaia argentina Wygodzinsky (M, DM).

Outgroup representatives studied: Pachynomidae: Aphelonotus sp. (M), Pachynomus picipes (Klug) (M), Punctius alutaceus (Stål) (F).

Terminology of antennal sclerites follows Zrzavý (1990a). The terms "external" and "internal face" of the antenna refer to the lateral and medial side respectively when the antenna is directed anteriorly (Fig. 1a).

\section{Abbreviations. \\ ann - antennal nerve \\ anv - antennal vessel \\ bf - basiflagellum}

bscco - base of sensory cell with hairlike projection of cave organ

cc - cuticular cylindre of trichobothrial socket

cco - cavity of cave organ

$\mathrm{cd}$ - circular depression surrounding trichobothrial socket

co - cave organ

cs - campaniform sensillum

csscl - campaniform sensillar sclerite of the pedicellopreflagelloidal membrane

$\mathrm{d}$ - dendrite of trichobothrial sensory cell

dco - duct of cave organ

do - dome-shaped part of the trichobothrial socket

$\mathrm{dscl}$ - dorsal sclerite of the pedicello-preflagelloidal membrane

en - endocuticle

ep - epidermis

ex - exocuticle

oco- opening of cave organ

om - oval membrane surrounding the distalmost trichobnothrium

ped - pedicel

pf - preflagelloid

pm - pedicello-preflagelloidal membrane

pscco - projection of sensory cell of cave organ

rlc - receptor lymph cavity

$\mathrm{sec}-$ sensory cell of trichobothrium

$\mathrm{sc}-$ scolopidial sensillum

sca-scape

se - elongated dorsal seta at the base of the pedicel in Peiratinae

tr - trichobothrium

tra - trachea

trb - basal plate of trichobothrial seta

ts - trichoid seta

vlscl - ventrolateral sclerite of the pedicello-preflagelloidal membrane

vmscl - ventromedial sclerite of the pedicello-preflagelloidal membrane 
a

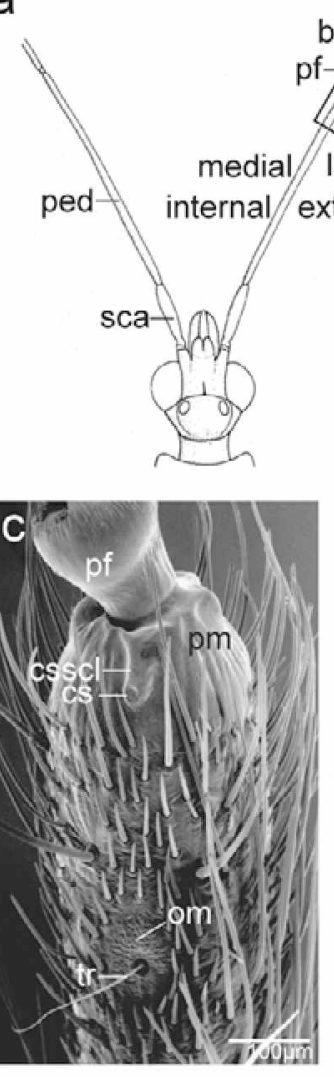

b

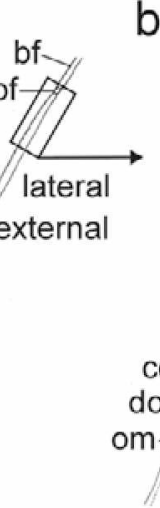

(1)

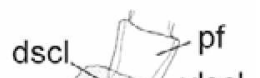

$-2-v i s c l$ $\mathrm{pm}$

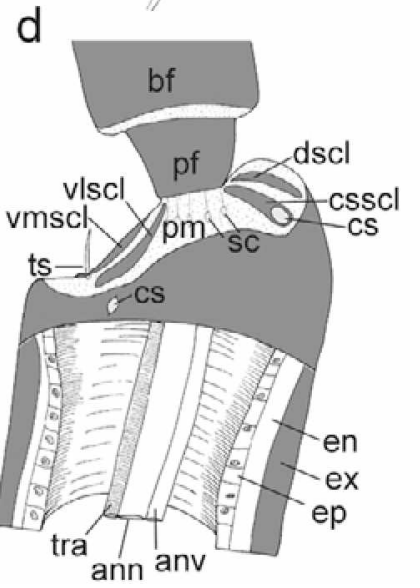

Fig. 1. Pedicellar structures in Reduviidae. a - Reduvius tenuicornis, male, dorsal aspect of head; $\mathrm{b}$-Reduvius tenuicornis, male, distal portion of right antennal pedicel, showing distalmost trichobothrium, cave organ and structures of the pedicello-flagellar articulation; c - Platymeris biguttata, male, SEM of distal portion of left pedicel, showing position of the distalmost trichobothrium and the sclerite surrounding the campaniform sensillum; d - Peirates sp., 5th instar nymph, reconstruction of pedicello-flagellar articulation, showing position of the four sclerites. Abbreviations: ann - antennal nerve (exterior of the two antennal nerves); anv - antennal vessel; bf - basiflagellum; cco - cavity of cave organ; cd - circular depression surrounding trichobothrium; cs - campaniform sensillum; csscl - campaniform sensillar sclerite; dco - duct of cave organ; do dome-shaped part of trichobothrial socket; dscl - dorsal sclerite; en - endocuticle; ep - epidermis; ex - exocuticle; oco - opening of cave organ; om - oval membrane; ped - pedicel; pf - preflagelloid; pm - pedicello-preflagelloidal membrane; sc - scolopidium; sca - scape; tr - triche; tra - trachea; ts - trichoid seta; vlscl - ventrolateral sclerite; vmscl - ventromedial sclerite bearing trichoid seta.

\section{RESULTS}

\section{Cave organ}

The antennal pedicel of Peiratinae, Reduviinae, Stenopodainae and Triatominae may possess a cuticle-lined invagination, which will subsequently be referred to as cave organ. However, the cave organ was not found in all representatives of these taxa. Among Stenopodainae, the cave organ is present in Oncocephalus sp., Pnirontis sp., Pygolampis bidentata, Pygolampis spurca and Staccia diluta, but it was not found in Apronius octonotatus, Diaditus sp., Kodormus bruneosus, Stenopoda subinermis and Thodelmus impicticornis. In Reduviinae, a cave organ is present in Acanthaspis sp., Centrogonus signatipennis, Edocla sp., Leogorrus liturata, Opisthacidius chinai, Paredocla planquettei, Platymeris biguttata, Reduvius personatus, Reduvius tenuicornis and Zelurus spinidorsis, whereas no cave organ was observed in Alloeocranum maculatum and the two species of Velitra studied. Among Peiratinae, only Peirates stridulus has a cave organ. Among the taxa of Triatominae which were not studied by Catalá et al. (1998), Eratyrus mucronatus and Panstrongylus geniculatus also possess a cave organ, whereas this structure was not found in Dipetalogaster maximus.

There is no cave organ in any representative of Phymatinae, Holoptilinae, Hammacerinae, Ectrichodiinae, Saicinae, Emesinae, Cetherinae, Physoderinae, Salyavatinae, Tribelocephalinae, Vesciinae or of the harpactoroid groups. Furthermore, no cave organ was found in Aphelonotus sp., Pachynomus picipes and Punctius alutaceus (Pachynomidae), representatives of the sistertaxon of Reduviidae (Carayon \& Villiers, 1968; Schuh \& Štys, 1991). The cave organ is also absent in nymphs of those species whose adults possess this organ (Oncocephalus $\mathrm{sp}$., Reduvius personatus, Platymeris biguttata).

The cave organ in Stenopodainae, Reduviinae, Peiratinae and Triatominae is observed in a corresponding position within the distal portion of the pedicel, with the opening ventral and proximal to the distalmost trichobothrium (Fig. 1b). The cave organ shows a high degree of fine structural resemblance in representatives of these taxa. The cuticle-lined duct invaginates from the opening without possessing sensory projections (Fig. 2a, c). The duct opens into a cavity whose integument bears sensory projections (Fig. 2a, c, d). The size of the cavity ranges from $30 \mu \mathrm{m}(P$. bidentata) to $140 \mu \mathrm{m}(P$. biguttata). The number of sensory projections within the cavity may range from about 20 in Redwivs spp. and Oncocephalus sp. to over 100 in P. biguttata (Fig. 2b) and O. chinai.

\section{The pedicello-flagellar articulation}

The pedicello-flagellar articulation is here described in some detail because of its relevance as a landmark for the recognition of the distalmost trichobothrium in Reduviidae and Pachynomidae. A cylindrical sclerotisation, the preflagelloid, is present between pedicel and basiflagellum in Reduviidae and Pachynomidae (Fig. 1b, c, d), as it is in many other Heteroptera (Zrzavý, 1990a). The less sclerotised region between pedicel and preflagelloid is thus termed the pedicellar-preflagelloidal membrane. Four elongated sclerites are embedded in this membrane in Pachynomus picipes and in Reduviidae (Fig. 1d). Three of these sclerites are visible from the external side of the pedicel. Among these, the dorsal sclerite and the ventrolateral sclerite are slender stripes without associated sensory structures. The sclerite beneath the dorsal sclerite bears proximally a large campaniform sensillum in all Reduviidae and in Pachynomus picipes. This sclerite is therefore termed the campaniform 


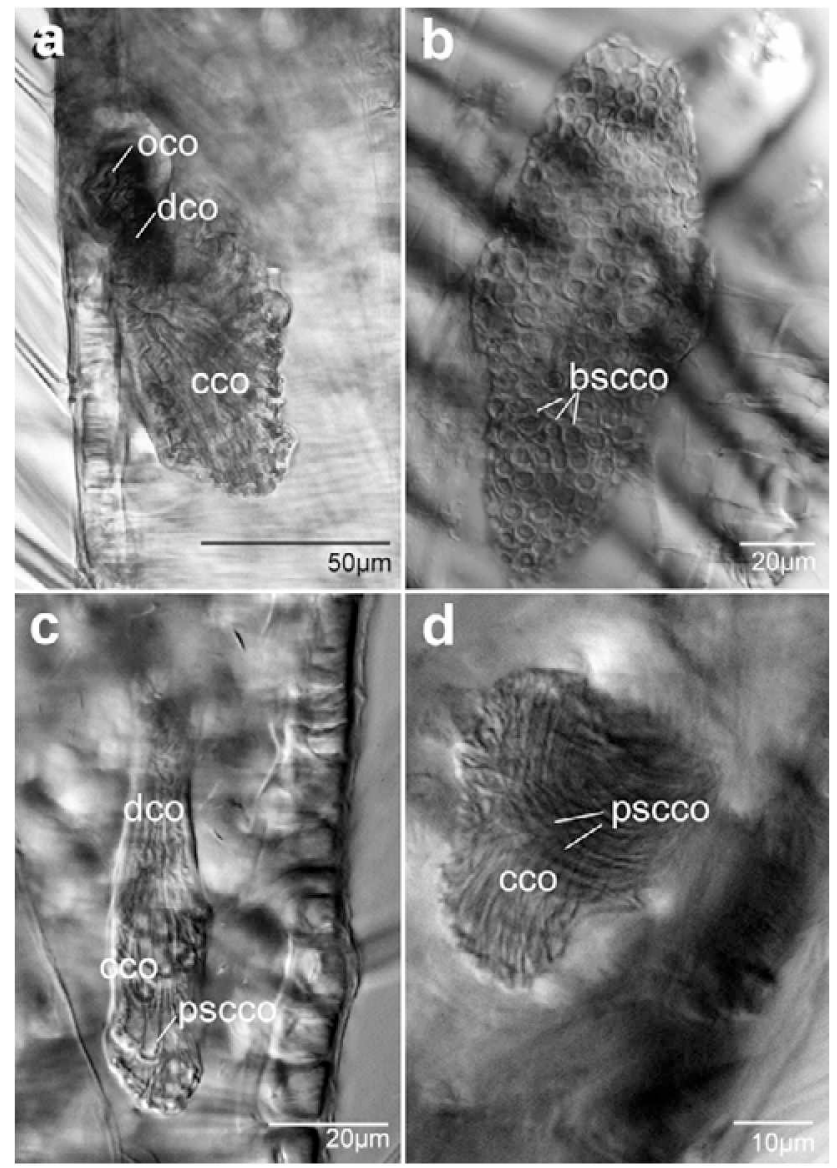

Fig. 2. Cave organ in Reduviidae. a - Zelurus spinidorsis, male, lateral aspect of cave organ, showing duct and cavity; bPlatymeris biguttata, male; ventral aspect of cave organ; the circular sclerotisations are bases of individual sensory cells; c Oncocephalus sp., female, ventrolateral view of cave organ, showing the slender cavity; d - Peirates sp., female, lateral view of cave organ. Abbreviations: bscco - base of sensory cell of cave organ; cco - cavity of cave organ; dco - duct of cave organ; oco - opening of cave organ; pscco - projection of sensory cell of cave organ.

sensillar sclerite. The fourth and ventromedial sclerite is located ventrally on the internal side of the pedicel and bears a single short trichoid seta on its proximal tip (Fig. 1d). The four sclerites may differ in the degree of sclerotisation among taxa and may thus sometimes be hard to detect. The relative length of the dorsal sclerite and the campaniform sensillar sclerite usually does not exceed the extension figured (Fig. 1d). However, in Eupheno pallens and Cethera musiva, the dorsal and campaniform sensillar sclerites are very long and slender.

Many scolopidia are attached to the pedicellarpreflagelloidal articulation in Pachynomus picipes and Reduviidae. These scolopidia constitute Johnston's organ (Fig. 1d).

\section{Trichobothria: Fine structure, systematic distribution} and homology

Trichobothria are delicate mechanoreceptive setae, comprising a long and thin seta and a usually prominent socket (Fig. 3). The externally visible portion of the tri- chobothrial socket is dome-shaped (Fig. 3c, d, e, f, h). The socket continues internally as a sclerotised cylinder (Fig. 3h). In Reduviidae and in Pachynomus picipes, the socket is usually set within a circular depression of the cuticle which may bear cuticular ridges (Fig. 3c, d). The base of the trichobothrial seta is enlarged into a basal plate (Fig. 3h). The trichobothrium is innervated by one sensory neuron in Triatoma dimidiata (Fig. 3h). Further, the trichobothrium, including the circular depression, may be surrounded by an oval or circular weakly sclerotised area in Reduviidae and in $P$. picipes (Fig. 3a, h), referred to as the oval or circular membrane in this study.

The systematic distribution of trichobothria in Reduviidae and Pachynomidae was examined in detail by Wygodzinsky \& Lodhi (1989), supplemented by Zrzavý (1990b), and is summarised here briefly: The majority of adult Reduviidae possesses numerous pedicellar trichobothria, whereas Pachynomus picipes, Phymatinae, Centrocneminae, Phimophorinae and part of Hammacerinae have only one trichobothrium. Nymphs of Reduviidae are usually equipped with only a single trichobothrium, although nymphs of Harpactorinae and Apiomerinae possess several trichobothria. Before these data may be employed in a systematic analysis, several questions should be addressed: Is the single trichobothrium of Pachynomus picipes homologous with one individual trichobohrium observed in Reduviidae, possibly the distalmost trichobothrium of Reduviidae which appears to be in a similar position? Is the single trichobothrium present in some Reduviidae homologous with an individual trichobothrium in the remaining reduviid taxa and/or the single trichobothrium present in Pachynomidae? Which of the adult trichobothria is the one already present in nymphs?

\section{What is the homologue of the single trichobothrium of Pachynomidae among the trichobothria in Reduviidae?}

The single trichobothrium in Pachynomus picipes is situated in line with the campaniform sensillar sclerite on the external side of the distal portion of the pedicel. In Reduviidae, the distalmost of the pedicellar trichobothria is observed to be in the same position relative to the campaniform sensillar sclerite (Fig. 1b). Further, a lightcoloured oval membrane, recognised in the SEM by its rippled surface, surrounds the single trichobothrium in all Pachynomidae and occurs in most Reduviidae exclusively around the distalmost trichobothrium (Fig. 1b, c, 3a, h). The distalmost trichobothrium in Reduviidae and the single trichobothrium in Pachynomus picipes are thus proposed to be homologous based on their position relative to the campaniform sensillar sclerite and on the structure of the surrounding cuticle.

Both criteria also apply for the distalmost trichobothrium in Chopardita mira (Vesciinae). However, the distalmost trichobothrium in this species is set in the middle of the pedicel rather than close to the pedicelloflagellar articulation. 

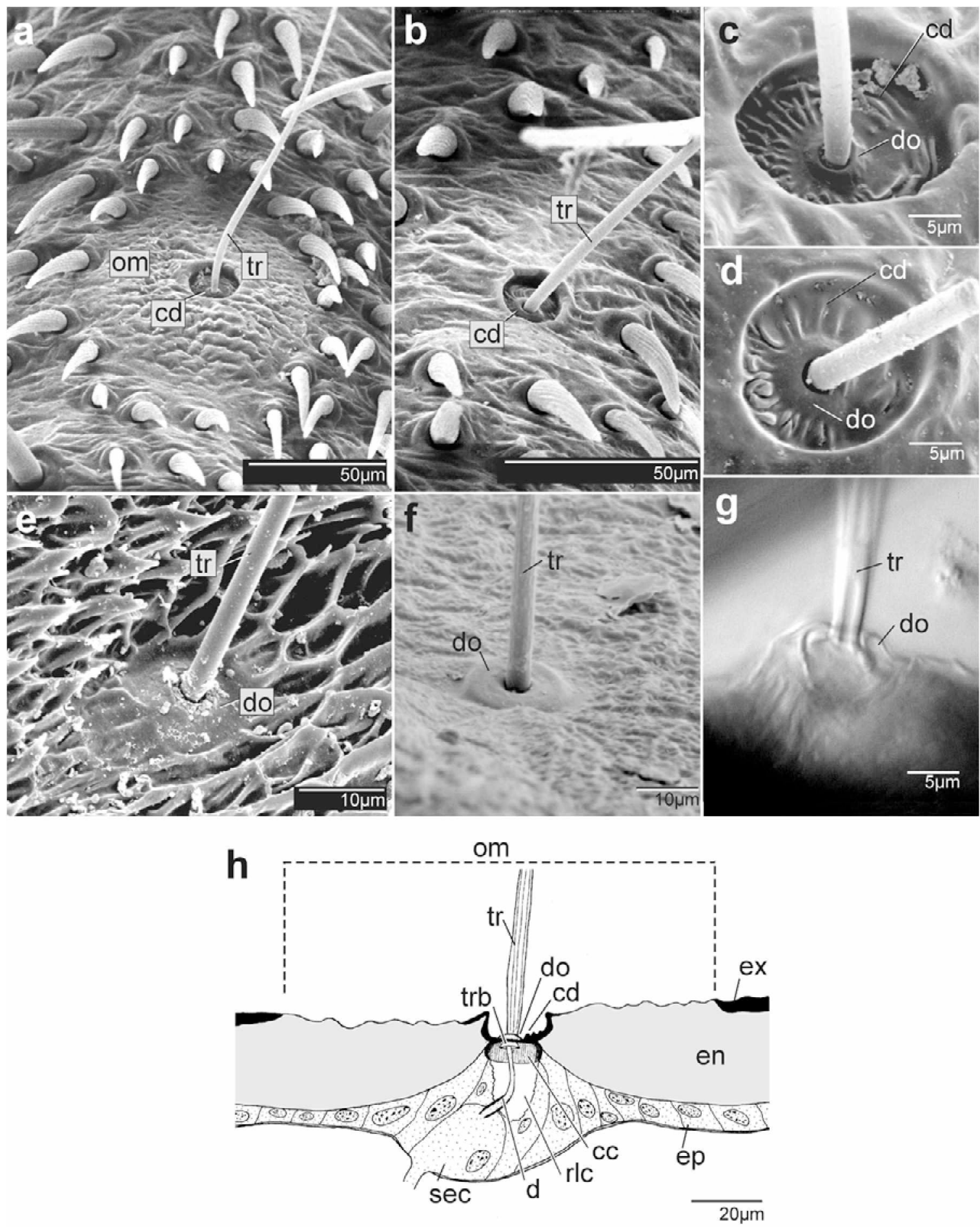

Fig. 3. Pedicellar trichobothria in Reduviidae. a - Platymeris biguttata, distalmost trichobothrium; $\mathrm{b}-P$. biguttata, one of the proximal trichobothria; $\mathrm{c}-P$. biguttata, circular depression of distalmost trichobothrium; $\mathrm{d}-P$. biguttata, circular depression of one of the proximal trichobothria; e - Phymata praestans, trichobothrial socket; f - Microtomus sp., trichobothrial socket; $g$ - Ptilocnemus sp., trichobothrial socket; $\mathrm{h}$ - Triatoma dimidiata, 5th instar nymph, reconstruction of trichobothrium from histological sections. Abbreviations: $\mathrm{cc}$ - cuticular cylindre of trichobothrial socket; $\mathrm{cd}$ - circular depression surrounding trichobothrial socket; $\mathrm{d}-$ dendrite; do - dome-shaped part of the trichobothrial socket; en - endocuticle; ep, epidermis; ex - exocuticle; om - oval membrane; rlc - receptor lymph cavity; sec - sensory cell; tr - trichobothrial seta; trb - base of trichobothrial seta.

Is the single pedicellar trichobothrium in Phymatinae, Holoptilinae and Hammacerinae homologous with the single trichobothrium in Pachynomidae and thus with

\section{the distalmost trichobothrium of remaining Reduviidae?}

The single trichobothrium in Phymatinae, Holoptilinae and some Hammacerinae is situated in the same position 
relative to the campaniform sensillar sclerite of the pedicello-flagellar articulation as the single trichobothrium in Pachynomidae and the distalmost trichobothrium in the remaining Reduviidae. However, no oval membrane surrounds the trichobothrium in these taxa. Furthermore, the trichobothrial socket is not located within a circular depression as in the trichobothria of the remaining taxa of Reduviidae and in $P$. picipes. Only the weakly elevated dome of the trichobothrial socket surrounds the base of the trichobothrial seta in Phymata praestans (Fig. 3e) and in Microtomus sp. (Fig. 3f). Zrzavý (1990b) believed trichobothria to be absent in Holoptilinae. A single distal trichobothrium, however, was found in a representative of Ptilocnemus sp. (Fig. 3g) in this study. The trichobothrium in Ptilocnemus is distinguished from the surrounding setae by its prominent socket (socket of setae narrow), by its length $(294 \mu \mathrm{m} ; \mathrm{n}$ $=1$; setae: $207.7 \pm 6.6 \mu \mathrm{m} ; \mathbf{n}=4)$ and its diameter $(3.45$ $\mu \mathrm{m}$ at base; setae: $4.8 \pm 0.3 ; \mathrm{n}=3$ ). As in $P$. praestans and Microtomus sp., neither a circular depression nor an oval membrane are present in Ptilocnemus sp.

The distally located single trichobothrium of Centrocneminae remains to be studied in detail, as does the single trichobothrium of Phimophorinae. For the hammacerine genus Homalocoris a basal trichobothrium was described in addition to the distal trichobothrium (Wygodzinsky \& Lodhi, 1989). My observation indicates, however, that this basal structure is a long and slender seta instead of a trichobothrium.

\section{Which trichobothrium of adult Reduviidae is the single trichobothrium of nymphs?}

The single trichobothrium present in most nymphs is set in exactly the same position on the pedicel relative to the campaniform sensillar sclerite as the distalmost trichobothrium of the adult. Further, the oval membrane characteristic of the distalmost trichobothrium in the adult also occurs around the single nymphal trichobothrium (Fig. 3h). Thus, ontogenetic persistence of the single trichobothrium of the nymph as the distalmost trichobothrium in the adult is hypothesised. This is further corroborated by examination of a pharate adult of Platymeris bigutta (hence still enclosed in the cuticle of the $5^{\text {th }}$ nymphal instar): The distalmost adult trichobothrium in this specimen was visible just beneath the single nymphal trichobothrium.

In nymphs of Microtomus sp. and Phymata monstrosa, a single trichobothrium is present in the same position as in the adult. Corresponding to the condition in their adults, they lack the oval membrane and circular depression.

As observed by Wygodzinsky \& Lodhi (1989), nymphs of Harpactorinae and Apiomerinae possess more than one trichobothrium. Observations on nymphs of Ectinoderus nitidus and Diaspidius sp. in this study indicate, that they are also equipped with several proximal trichobothria in addition to the single, distal trichobothrium of remaining reduviid nymphs.

Nymphs of Pachynomidae are unknown (Schuh \& Slater, 1995).

\section{The proximal trichobothria}

In the majority of Reduviidae, a proximal row of trichobothria is present in addition to the distalmost trichobothrium. For documentation see Zrzavý (1990b) and Wygodzinsky \& Lodhi (1989). There is no oval membrane surrounding the socket of these proximal trichobothria in Cetherinae, Ectrichodiinae, Physoderinae, Reduviinae, Salyavatinae, Stenopodainae, Triatominae, Tribelocephalinae, Saicinae and Emesinae (Fig. 3b). However, exceptions are observed in Peiratinae and harpactoroid groups. In Peiratinae all trichobothria are surrounded by an oval membrane (Fig. 4a-d) similar to the membrane of the distalmost trichobothrium in other Reduviidae. In Apiomerinae, Harpactorinae and Tegeinae the trichobothria of the proximal row are surrounded by small circular membranes. Their diameters differ along the pedicel: They tend to be narrower around the more proximal trichobothriathan around the more distally located trichobothria.

\section{Are there features to distinguish and homologise individual proximal trichobothria?}

The number of trichobothria differs between species as well as between higher level taxa. Trichobothria are mostly of similar length. Furthermore, the structure of the socket and surrounding cuticle does not provide diagnostic characters and the position of individual trichobothria is hard to define due to lack of landmarks. In many Reduviidae, the more proximal trichobothria tend to be located more ventrally than the more distal trichobothria (see Wygodzinsky \& Lodhi, 1989: e.g., Figs 11d, $12 \mathrm{c}, 13 \mathrm{~b}$ ). However, this tendency does not provide clear cut characters. Homology of individual proximal trichobothria between higher level taxa thus appears to be impossible so far.

However, within one of these taxa, the Peiratinae, homologues might be tentatively proposed.

\section{Homology of trichobothria in Peiratinae}

Peiratinae possess a total of 10 or 11 trichobothria. All trichobothria are surrounded by an oval membrane, which renders one of the criteria identifying the distalmost trichobothrium in other Reduviidae inapplicable. The trichobothrium closest to the pedicello-flagellar articulation is furthermore not exactly in line with the campaniform sensillar sclerite, but set more ventrally. Therefore, homology of the distalmost trichobothrium of Peiratinae with the distalmost in other Reduviidae is likely but tentative. In Peiratinae, a large basal campaniform sensillum of apparently stable position, a very stout and elongated dorsal seta, and an area without trichobothria provide additional landmarks. The length of individual trichobothria differs and the position of individual trichobothria may be described employing their orientation and relation to other trichobothria.

For Rasahus amapaensis, which possesses 11 trichobothria, numbers were introduced referring to individual trichobothria. The numbering proceeds from the base to the tip of the pedicel and the following features charac- 


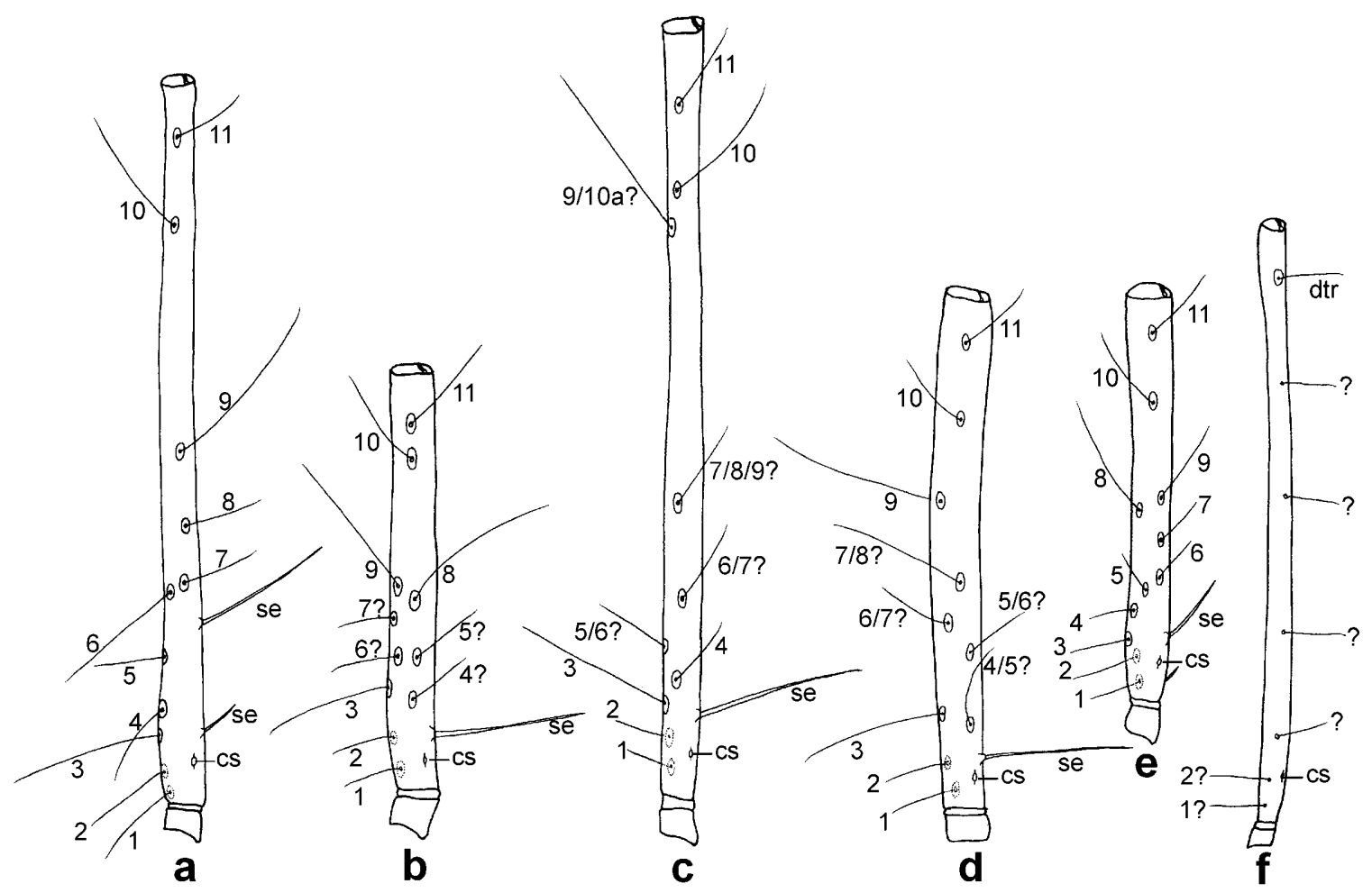

Fig. 4. Homology of pedicellar trichobothria in different Peiratinae and Reduvius personatus (Reduviinae). Pedicel of left antenna seen from external side; in the drawing the dorsal side is on the right, the distal is on top. $\mathrm{a}-$ Rasahus amapaensis; $\mathrm{b}-$ Sirthenea stria; $\mathrm{c}$ - Tydides rufus; $\mathrm{d}$ - Melanolestes morio; e - Peirates stridulus; $\mathrm{f}$-Reduvius personatus. Abbreviations: cs - campaniform sensillum, dorsally at the base of the pedicel; dtr-distalmost trichobothrium; se - dorsal seta at the base of the pedicel in Peiratinae.

terise the given trichobothrium in $R$. amapaensis (Fig. 4a).

Trichobothria 1 to 3 are set ventromedially on the pedicel and they point ventrally. A campaniform sensillum lies closest to trichobothrium 2. Trichobothrium 3 is longer than trichobothria 1 and 2. Trichobothria 4 and 5 are positioned ventrally and in one line. Trichobothria 6 and 7 are located on the external side and are set very close to each other. Trichobothrium 6 is very long. Trichobothrium 8 is observed also on the external side; it is in line with trichobothrium 7 and about half way between trichobothrium 7 and 9. Trichobothrium 9 is also located on the external side, is extremely long and proximal to a region which lacks trichobothria. Trichobothria 10 and 11 are set on the external side in line with each other, and are separated from the more proximal trichobothria by the area devoid of trichobothria, a "gap".

Trichobothrial arrangement in representatives of other genera of Peiratinae was compared to this scheme and homology was proposed for individual trichobothria which were numbered accordingly.

The homology of trichobothria 1 to 3 in R. amapaensis, Sirthenea stria, Tydides rufus, Melanolestes morio and Peirates stridulus is proposed due to their ventromedial position (Fig. 4a-e). Trichobothrium 3 is longer than the two proximal trichobothria also in $S$. stria, T. rufus and M. morio. Homology of trichobothria 10 and 11 also appears to be rather unambiguous. They are observed in a distal position on the pedicel, separated by the "gap" also in S. stria, T. rufus, M. morio and P. stridulus. However, in T. rufus, a third trichobothrium is close to them, which might be either a trichobothrium without homologue in other taxa ("10a") or trichobothrium 9 set more distally than in other Peiratinae. Homology of trichobothrium 9 among Peiratinae may also be proposed due to its position proximad of the "gap". However, its identity is uncertain in T. rufus. The situation is less clear cut among trichobothria 4 to 8 , for which homologies are proposed only tentatively (Fig. 4b-d).

However, problems arise when this scheme is transferred to other subfamilies of Reduviidae. On the pedicel of Reduvius personatus (Reduviinae) (Fig. 4f) only 7 trichobothria are observed. The two most proximal trichobothria might be homologous to trichobothria 1 and 2 in Peiratinae, because of their proximity to the campaniform sensillum and rather ventral position. For the remaining trichobothria, all of equal and moderate length and similar orientation, no proposition of homology was attempted.

\section{DISCUSSION}

\section{Implication of systematic distribution of the cave organ within Reduviidae.}

Based on fine structure (Fig. 1c-f) and position (Fig. 1a), homology of the cave organ described in Triatominae by Barth (1952) and Catalá et al. (1998) with the structure described in Stenopodainae, Peiratinae and Reduviinae in this study is proposed (Table 1). This sensillar structure is absent in the remaining Reduviidae as well as in Pachynomidae. The cave organ might thus present an apomorphy of Triatominae, Stenopodainae, Peiratinae and 
TABLE 1. Systematic distribution of pedicellar structures among higher rank taxa of Reduviidae, and Pachynomidae. Structure: +: present, - : absent,,+- : present in some representatives of the taxon, absent in others; ?: condition unknown.

\begin{tabular}{|c|c|c|c|c|}
\hline & $\begin{array}{l}\text { Cave } \\
\text { organ }\end{array}$ & $\begin{array}{c}\text { Distalmost } \\
\text { trichobothrium }\end{array}$ & $\begin{array}{c}\text { Oval } \\
\text { membrane }\end{array}$ & $\begin{array}{c}\text { Proximal } \\
\text { trichobothria }\end{array}$ \\
\hline Apiomerinae & - & + & + & + \\
\hline Centrocneminae & - & + & $?$ & - \\
\hline Cetherinae & - & + & + & + \\
\hline Diaspidinae & - & + & + & + \\
\hline Ectinoderinae & - & + & + & + \\
\hline Ectrichodiinae & - & + & + & + \\
\hline Emesinae & - & + & + & + \\
\hline Hammacerinae & - & + & - & - \\
\hline Harpactorinae & - & + & + & + \\
\hline Holoptilinae & - & + & - & - \\
\hline Peiratinae &,+- & + & + & + \\
\hline Phymatinae & - & + & - & - \\
\hline Physoderinae & - & + & + & + \\
\hline Reduviinae &,+- & + & + & + \\
\hline Saicinae & - & + & + & + \\
\hline Salyavatinae & - & + & + & + \\
\hline Stenopodainae &,+- & + & + & + \\
\hline Tegeinae & - & + & + & + \\
\hline Triatominae &,+- & + & + & + \\
\hline $\begin{array}{l}\text { Tribelocepha- } \\
\text { linae }\end{array}$ & - & + & + & + \\
\hline Vesciinae & - & + & + & + \\
\hline Pachynomidae & - & + & + & - \\
\hline
\end{tabular}

Reduviinae. However, this structure is absent in several taxa of Peiratinae, Reduviinae and Stenopodainae as well as Dipetalogaster maximus among Triatominae. Several hypotheses may be formulated in order to explain the observed systematic distribution of the cave organ: Assuming the monophyly of each of the taxa involved (Peiratinae, Reduviinae, Stenopodainae,Triatominae), the absence of the cave organ in representatives of these taxa might be interpreted as secondary loss. However, at least for Reduviinae, no conclusive evidence for monophyly has been established yet, and possibly Reduviinae possessing a cave organ might be more closely related to Stenopodainae, Peiratinae and Triatominae than Reduviinae without this structure. Finally, the cave organ might have been acquired independently within each taxon, but this appears unlikely judging from the corresponding fine structural detail. In order to test these hypotheses, a phylogenetic analysis of reduviid higher taxa has to be conducted including the presence of the cave organ as one of the characters, thus testing its congruence with other characters. Further, several higher level taxa remain to be investigated for the cave organ (e.g. Sphaeridopinae).

Prior to this study, the cave organ was only reported for Triatominae (Catalá et al., 1998). The monophyly of Triatominae was suggested by Lent \& Wygodzinsky (1979), based on sparse morphological evidence, but was not accepted by all authors (Schofield, 1988). Recently, the hypothesis on monophyletic Triatominae was corrobo- rated by a molecular study (Hypša et al., 2002). However, not much evidence has been published with regard to possible sistergroups of Triatominae. Lent \& Wygodzinsky (1979) tentatively suggested Physoderinae as the possible sistertaxon based on what appears to be rather superficial similarity of the labium. The presence of the cave organ in representatives of Stenopodainae, Peiratinae and Reduviinae - but not in Physoderinae- suggests that the sistertaxon of Triatominae might be found among these taxa.

\section{No cave organ in Ectrichodiinae}

Dougherty (1985) reported a "Barth's organ" in Ectrichodiinae. She described and illustrated a "light-coloured, membranous oval" associated with the distalmost trichobothrium and deduced from this external feature the presence of a structure homologous with the organ described by Barth (1952) in Triatominae. My results indicate that no relation exists between the oval membrane surrounding the distalmost trichobothrium on one hand and the presence of the cave organ on the other. A cave organ sensu Barth (1952) and Catalá et al. (1998) was not found in Ectrichodiinae in this study.

\section{Comment on structure and possible functions of the cave organ}

The dimensions of the cave organ within Triatominae, Peiratinae, Reduviinae and Stenopodainae may differ among species. Catalá et al. (1998) presented drawings of the cave organ of four Triatoma-species, indicating that the length of the cavity in this genus may range between $40 \mu \mathrm{m}$ in Triatoma sordida and $150 \mu \mathrm{m}$ in Triatoma dimidiata. Catalá et al. (1998) stated that size of the cave organ does not correlate with the dimensions of the pedicel. However, the larger specimens of $T$. dimidiata actually possess a more spacious cave organ than the small individuals of $T$. sordida, indicating that there might by a correlation between body size and size of the cave organ after all. This correlation is also reflected by the small cave organ of Pygolampis (small individuals) versus the large cave organ in Platymeris biguttata (one of the largest Reduviidae).

Possible functions suggested for the cave organ in haematophagous Triatominae are heat sensation for locating a vertebrate host (Barth, 1952), sensation of thermal stimuli (Lazzari \& Wiklein, 1994) and olfactory reception, "possibly enabling molecular testing during flight" (Catalá et al. 1998). In those Reduviidae which are known to prey on arthropods, e.g., Stenopodainae, Reduviinae and Peiratinae, a function of the cave organ as a heat receptor in the context of prey location is unlikely. The ultrastructural description of the cave organ receptors (Catalá et al., 1998) appears to correspond to that of chemoreceptive sensilla (Altner \& Prillinger, 1980). An accumulation of olfactory receptors in a depression on the antennal funiculus was described by Kaissling (1971) in calyptrate flies and postulated to be stimulated especially during flight. This might be also true for the reduviid cave organ, as stated by Catalá et al. (1998), although air movement into the blind cavity via the narrow duct should be rather restricted. Further, a well developed cave 
organ is present in males and females of the apterous Paredocla planquettei, indicating that this structure may also function on the ground.

No sexual dimorphism was observed for the cave organ and it was never found in a nymph.

\section{The pedicello-basiflagellar articulation and the pedicel} in Pachynomus picipes

The totality of structures associated with the membrane between the pedicel and preflagelloid defines unambiguously the pedicello-basiflagellar articulation in Reduviidae as well as in Pachynomus picipes.

In Pachynomidae, the antenna does not consist of scape, pedicel and two flagellomeres as in Reduviidae, but comprises five articles separated by intercalary nodes (Carayon \& Villiers, 1968). The presence of the single trichobothrium on the third article in Pachynomidae, which was proposed to be homologous with one of the pedicellar trichobothria in Reduviidae, led to the assumption that in Pachynomidae it is the pedicel which has undergone division (Wygodzinsky \& Lodhi, 1989). On the other hand, the pachynomid trichobothrium was proposed to be homologous with one of the trichobothria in Reduviidae because of its presence on the pedicel, leading to some circularity of reasoning. Zrzavý (1990a) reported the subdivision of the pedicel in Pachynomidae, and the presence of an intrapedicelloid, without specifying his arguments. Here, the pedicello-basiflagellar articulation is identified with reference to the sclerites and sensory structures described - structures not present on or around the intrapedicelloid- , thus corroborating the assumption of a subdivided pedicel in Pachynomidae, with the trichobothrium being located on its distal portion.

The sensory structures associated with the sclerites of this articulation, the dorsal campaniform sensillum and the ventromedian trichoid sensillum, may play a role in monitoring the position of the flagellomeres in addition to Johnston' s organ. Trichoid setae are commonly found in insects around joints, assisting there in proprioception as are campaniform sensilla (Chapman, 1991).

\section{Implication of systematic distribution of trichobothria}

The single trichobothrium in Pachynomidae and the distalmost trichobothrium in Reduviidae are homologous based on position and fine structure including the circular depression and the oval membrane surrounding the socket (Table 1). Presence of this trichobothrium is a synapomorphy for Pachynomidae and Reduviidae.

An oval structure around the distalmost trichobothrium was illustrated for several taxa by Wygodzinsky \& Lodhi (1989), but the authors did not comment on its nature. Further, Dougherty (1985) reported the presence of a "membranous oval" in Ectrichodiinae. The oval membrane in Reduviidae appears to conform to the definition of a trichoma presented by Schuh (1975), who referred to it as a "group of spicules or a modified cuticular area" surrounding the trichobothrium. However, a field of microtrichia as around the femoral trichobothria of many Miridae (Schuh 1975) is not observed on the oval membrane of Reduviidae, and the trichoma in Miridae have not shown to be membranous. The two structures do not appear to be homologous.

An oval membrane around the distalmost trichobothrium as documented in this study is here assumed to be plesiomorphic for Reduviidae due to its presence in Pachynomidae. In contrast, no membrane is observed around the single trichobothrium in Hammacerinae, Phymatinae and Holoptilinae. However, this trichobothrium is assumed to be homologous to the distalmost trichobothrium in the remaining Reduviidae due to its position relative to the campaniform sensillar sclerite. The loss of the oval membrane surrounding the trichobothrium as well as the loss of the circular depression are derived features in these taxa. Hammacerinae, Holoptilinae and Phymatinae appear thus apomorphic in their loss of the membrane around the trichobothrial socket as well as the circular depression, but plesiomorphic in their possession of only one distal trichobothrium. Phymatinae and Holoptilinae together with Elasmodeminae have long been proposed to constitute a monophyletic group, the phymatin complex (Carayon et al., 1958), e.g., on the basis of their unique genitalia. The corresponding structure of the single trichobothrium in Microtomus sp. might indicate an affinity of Hammacerinae with this complex, if one assumes that loss of the circular depression and membrane did not occur independently in these taxa.

A single trichobothrium was also seen in Phimophorinae (Wygodzinslky \& Lodhi, 1989), which could not be investigated in this study. Further, data for Elasmodeminae are missing entirely.

The presence of a row or field of pedicellar trichobothria proximal of the distalmost trichobothrium is the derived condition within Reduviidae (Zrzavý, 1990b). This character is shared by Ectrichodiinae, Reduviinae, Peiratinae, Physoderinae, Stenopodainae, Triatominae, Tribelocephalinae, Cetherinae, Salyavatinae, Saicinae, Emesinae, representatives of the harpactoroid groups examined in this study and by Wygodzinsky \& Lodhi (1989), and Spaheridopinae and Vesciinae as observed by Wygodzinsky \& Lodhi (1989). The triatomine Belminus was cited by Zrzavý (1990b) as possessing only one trichobothrium. Wygodzinsky \& Lodhi (1989) illustrated one trichobothrium in Belminus peruvianus, but the two specimens of Belminus peruvianus figured by Lent \& Wygodzinsky (1979) possessed four trichobothria. Trichobothria are easily overlooked when broken off close to the socket, so four trichobothria may assumed to be present in Belminus.

Zrzavý (1990b) created a trichobothrial pattern of type $\mathrm{V}$ exclusively for Vesciinae, defined by the presence of only a few trichobothria proximally on the pedicel and thus suggesting the absence of a trichobothrium homologous to the distalmost trichobothrium in other Reduviidae. However, the distalmost trichobothrium in Chopardita mira is easily recognised by the oval membrane and its position in line with the campaniform sensillar sclerite. A possibly derived proximal shift of the distalmost trichobothrium towards the middle of the 
pedicel rather than the absence of this trichobothrium can thus be proposed for Chopardita mira.

Hypotheses on homology of individual trichobothria because of their relative position along the proximal portion of the pedicel do not appear to be formulated easily. Even within smaller groups such as Peiratinae, homology is proposed only tentatively. In Peiratinae, the supposition of homology relies on different lengths of trichobothria, positions in relation to each other and positions in relation to landmarks. Homology of the three most proximal trichobothria may be proposed, as well as that of the trichobothria 9 to 11 . These trichobothria should already have been present in this arrangement in the groundplan of Peiratinae. Assuming that trichobothria of equal and moderate length are plesiomorphic for Peiratinae, as this is the condition observed in most other Reduviidae, the long trichobothrium 3 in $R$. amapaensis, S. stria, T. rufus and $M$. morio and the long trichobothrium 9 in all Peiratinae might be derived for these taxa. So far, this scheme cannot be transferred to the pattern observed in other reduviid taxa.

In nymphs of most Reduviidae only the distalmost trichobothrium is present. The occurrence of several proximal trichobothria in nymphs as well as adults is a character shared by, and derived for, representatives of several of the harpactoroid groups. The presence of proximal trichobothria was demonstrated for Harpactorinae and Apiomerinae (Wygodzinsky \& Lodhi, 1989) and for Diaspidinae and Ectinoderinae (this study), and might thus be an additional character for uniting the harpactoroid groups.

ACKNOWLEDGEMENTS. I want to thank the following persons for kindly providing specimens for this study: Jean-Michel Bérenger (Aix-en-Provence), Jürgen Deckert (Museum für Naturkunde der Humboldt-Universität, Berlin), Jocelia Gracia (Universidade Federal do Rio Grande do Sul), Steffen Roth (Jena), Randall T. Schuh (American Museum of Natural History), Andreas Zwick (Tübingen). I am indebted to Ralf Britz and Randall T. Schuh for their comments on drafts of the paper. During this project, I was supported by a grant of the "Berliner Programm zur Förderung der Chancengeleichheit von Frauen in Forschung und Lehre" (Humboldt-Universität, Berlin).

\section{REFERENCES}

Altner H. \& Prillinger L. 1980: Ultrastructure of invertebrate chemo-, thermo., and hygroreceptors and its functional significance. Int. Rev. Cytol. 57: 69-139.

BARTH R. 1952: Estudos anatomicos e histologicos sobre a subfamilia Triatominae (Hemiptera: Reduviidae). II. Parte. Um novo orgao sensivel das Triatominae. Manguinhos. Bol. Inst. Oswaldo Cruz 1: 1-4.

Carayon J., Usinger R.L. \& Wygodzinsky P. 1958: Notes on the higher classification of the Reduviidae, with the description of a new tribe of the Phymatinae. Rev. Zool. Bot. Afr. 57 : 256-281.

Carayon J. \& Villiers A. 1968: Etude sur les hémiptères Pachynomidae. Ann. Soc. Entomol. Fr. (N. S.) 4: 703-739.
Catalá S. 1997: Antennal sensilla of Triatominae (Hemiptera: Reduviidae): a comparative study of five genera. Int. J. Insect Morphol. \& Embryol. 26: 67-73.

CATALÁ S. \& SCHOField C. 1994: The antennal sensilla of Rhodnius. J. Morphol. 219: 193-204.

Catalá S., Tomasi V., Huba E. \& Rovasio R. 1998: The cave organ in Triatominae (Hemiptera, Reduviidae) antennae: An olfactory receptor? Biocell 22: 1-7.

ChaPMan R.F. 1991: General anatomy and function. In: CSIRO (ed.): The Insects of Australia. A Textbook for Students and Research Workers. Melbourne University Press, Melbourne, pp. 33-67.

Davis N.T. 1969: Contribution to the morphology and phylogeny of the Reduvioidea. Part IV. The harpactoroid complex. Ann. Entomol. Soc. Am. 62: 74-94.

Dougherty V. 1985: A review of the New World Ectrichodiinae genera (Hemiptera: Reduviidae). Trans. Amer. Entomol. Soc. 121: $173-225$.

Gracco M. \& Catalá S. 2000: Inter-specific and developmental differences on the array of antennal chemoreceptors in four species of Triatominae (Hemiptera: Reduviidae). Mem. Inst. Oswaldo Cruz 95: 67-74.

Hypša V., Tietz D. F., Zrzavý J., Rego R.O.M., Galvao C. \& JuRBerg J. 2002: Phylogeny and biogeography of Triatominae (Hemiptera: Reduviidae): molecular evidence of a New World origin of the Asatic clade. Mol. Phylogen. Evol. 23: 447-457.

KAIssLing K.-E. 1971: Insect Olfaction. In: Beidler L.M. (ed.): Handbook of Sensory Physiology, Vol. IV; Chemical Senses. Springer-Verlag, Berlin, pp. 351-431.

LAZZARI C.R. \& WIKLEIN M. 1994: The cave-like sense organ in the antennae of Triatominae Bugs. Mem. Inst. Oswaldo Cruz 89: 643-648.

LENT H. \& WYGoDZInsky P. 1979: Revision of the Triatominae (Hemiptera, Reduviidae), and their significance as vectors of Chagas' disease. Bull. Amer. Mus. Nat. Hist. 163: 1-520.

McIver S.B. \& Siemicki R. 1984: Fine structure of antennal mechanosensilla of adult Rhodnius prolixus Stal (Hemiptera: Reduviidae). J. Morphol. 180: 19-28.

PuchKov P.V. 1987: Khishchnetsy. Fauna Ukrainy 21 (5). Naukova dumka, Kiev, 248 pp. [in Russian]

SCHAEFER C.W. 1975: Heteropteran trichobothria (Hemiptera: Heteroptera). Int. J. Insect Morphol. \& Embryol. 4: 193-264.

Schofield C. 1988: Biosystematics of the Triatominae. In: Service M.W. (ed.): Biosystematics of Haematophagous Insects. Systematics Association Special Volume 37. Clarendon Press, Oxford, pp. 284-312.

SCHur R.T. 1975: The structure, distribution, and taxonomic importance of trichobothria in the Miridae (Hemiptera). Amer. Mus. Novitates: No. $2584,26 \mathrm{pp}$.

Schur R.T. \& Slater J.A. 1995: True Bugs of the World (Hemiptera: Heteroptera). Classification and Natural Histrory. Cornell University Press, Ithaca, $336 \mathrm{pp}$.

SCHuH R.T. \& Š TYS P. 1991: Phylogenetic analysis of cimicomorphan family relationships (Heteroptera). J. N. Y. Entomol. Soc. 99: 298-350.

WYGodzINSKy P.W. \& LoDHI S. 1989: Atlas of antennal trichobothria in the Pachynomidae and Reduviidae (Heteroptera). $J$. N.Y. Entomol. Soc. 97: 371-393.

ZRZAVÝ J. 1990a: Evolution of antennal sclerites in Heteroptera (Insecta). Acta Univ. Carol. Biol. 34: 189-227.

ZRZAVÝ J. 1990b: Antennal trichobothria in Heteroptera: a phylogenetic approach. Acta Entomol. Bohemoslov. 87: 321-325.

Received September 18, 2002; revised January 29, 2003; accepted February 4, 2003 